\title{
Application of graphite-based sacrificial layers for fabrication of LTCC (low temperature co-fired ceramic) membranes and micro- channels
}

\author{
Hansu Birol, Thomas Maeder and Peter Ryser
}

École Polytechnique Fédérale de Lausanne (EPFL), Laboratoire de Production Microtechnique (LPM), CH1015 Lausanne, Switzerland

http://www.epfl.ch ; http://lpm.epfl.ch ; E-mail : thomas.maeder@epfl.ch

Version of record: Journal of Micromechanics and Microengineering 17 (1), 50-60, 2007.

http://hdl.handle.net/10.1088/0960-1317/17/1/007

\begin{abstract}
Fabrication of sensors and micro-fluidic structures from low temperature co-fired ceramic (LTCC) sheets is a growing interest in the micro-packaging community. Such devices usually have inner cavities, whose production is quite complicated. The most elegant method to build such structures so far achieved is by a fugitive phase that is introduced into the multilayer and removed during firing. This paper, therefore, is aimed to introduce the graphite-based sacrificial paste developed for this purpose and it is constructed in two sections: (i) selection of paste and determination of LTCC open-porosity elimination temperature, and (ii) fabrication and characterization of pressure sensitive LTCC membranes. In the former section, it is shown that increased heating rates (and decreasing tape thickness) shift the open porosity elimination temperature of LTCC by $20^{\circ} \mathrm{C}$, which is small compared to the shift of graphite oxidation temperature (about $100^{\circ} \mathrm{C}$ ). In the latter section, three parameters affecting the balance between the graphite oxidation and LTCC sintering are studied: heating rate, graphite phase thickness and width of the membrane inlet/outlet channels. As expected, larger heating rates and narrow inlet/outlet channels are found to hinder the oxidation of graphite and evacuation of the resulting products, which results in swollen membranes. Large graphite thickness, through the increased channel height, results in lower swelling in spite of the larger amount of graphite to be oxidized. Membranes with low swelling are found to exhibit excellent pressure sensing characteristics, whereas those with high swelling display hysteretic behavior.
\end{abstract}

\section{Introduction}

Application areas of low temperature co-fired ceramic (LTCC) technology have recently diversified further than its traditional use in the telecommunication sector [1, 2]. Versatile applications from sensors to micro-fluidic devices, at a range from tens of micrometers to millimeters [3, 9] have been demonstrated. The reasons for such diversification in applications can be ascribed to the characteristics of LTCC sheets or green tapes (after DuPont) such as plasticity and ease of machining at room temperature, full density at low firing temperatures, chemical inertness, integration with thick-film technology, increased functionality at reduced volumes etc.

The selection of fabrication technique for LTCC structures is mainly driven by the functional principle and the dimensions of the device. In some cases, direct lamination of LTCC multi-layers 
results in defects (e.g. dimensional variations of cavities), which impose no restrictions to further device application. However, in some other cases, where the cavities are not supported by a fugitive phase, defects such as sagging and disintegration of layers are frequently observed $[10,11]$.

There are few methods based on utilization of a fugitive phase that can be removed following/during firing [12-15], in addition to rarely cited chemical processes [16]. Various general requirements of a fugitive phase (sacrificial layer) are easy deposition into cavities or on tapes, shrinkage match to LTCC, chemical inertness to avoid interaction with tapes, sufficient ability to withstand lamination pressure, etc. [10].

In this study, we propose and explain the details of graphite-based sacrificial layers to avoid such defects, which have direct influence on device functionality [17-19]. The paste is prepared by mixing the graphite powder with organic vehicle, which is then homogenized on a three-roll mill (figure 1(a)) and screen printed on LTCC according to the pre-determined layout of the devicepressure sensitive LTCC membrane in this study (figure 1(b)). Printed LTCC layer is then laminated with blank LTCC layers (figure 2) and fired. Cavities are formed upon oxidation of the paste and the oxidation products such as $\mathrm{CO} / \mathrm{CO}_{2}$ degas through porous LTCC. The device is completed by gluing inlet and outlet ports using an epoxy resin (figures 2 and 3 ).
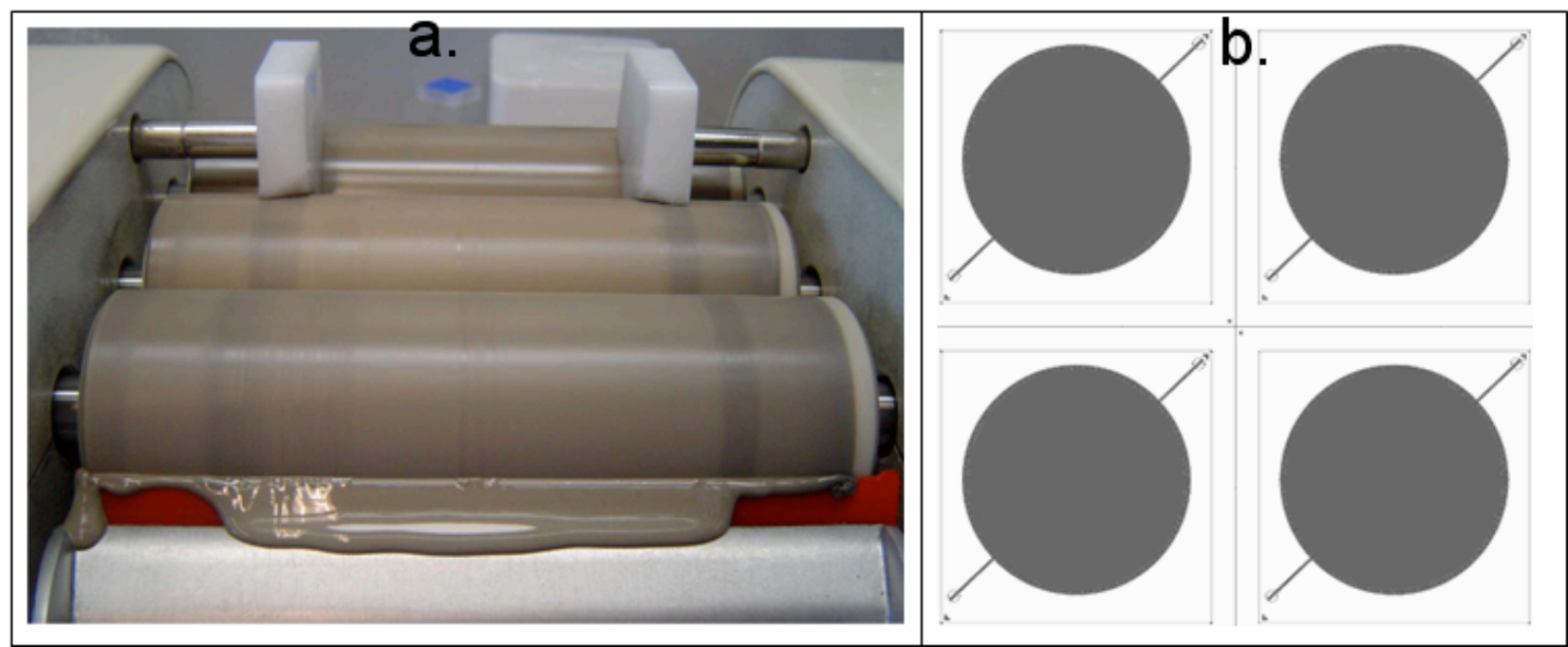

Figure 1. a. Paste homogenization on three-roll mill, b. Layout for graphite paste screen-printing. Four membranes on a single LTCC sheet are defined for series production (each membrane has a diameter of $22 \mathrm{~mm}$ and is on an area of $30 \times 30 \mathrm{~mm}^{2}$ LTCC).

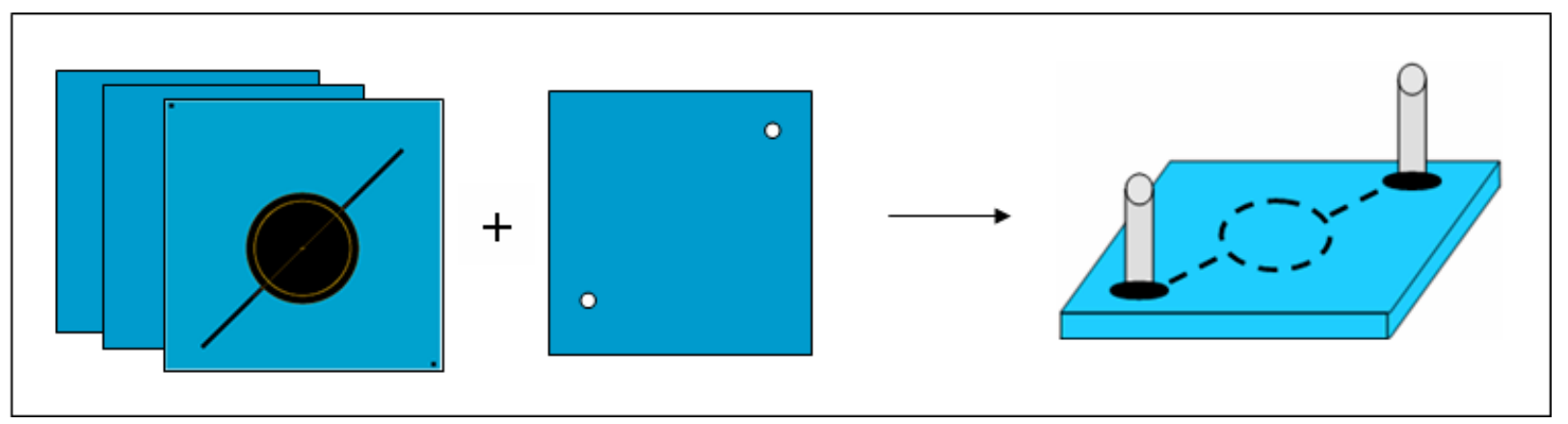

Figure 2. Sketch of the screen printed and laminated, single LTCC block (membrane and base are 50 and $762(3 \times 254) \mu \mathrm{m}$ thick LTCC layers, respectively, and the dashes indicate the printed paste area). 
Applicability of the technique requires complete information on two concurrent processes: paste burnout and LTCC open pore elimination. The kinetic competition between these events, with the influence of heating rate, is extremely important as it determines the mechanism of paste oxidation. Moreover, degassing of burnout products also depends on the order of these events. The air necessary for oxidizing the paste is acquired via porous LTCC and channels of the membrane, where the former constitutes the easiest burnout path (figure 4). Therefore, the closure of porosity in LTCC results in air intake being limited to the channels, retarding oxidation of the remaining paste. This results in swelling of the membrane, which occurs as a result of the increased gas pressure that is imprisoned in the cavity.

Effects of processing parameters - other than those related to paste and LTCC - on device features such as printed paste thickness and the width of the inlet and outlet channels of the membrane are also investigated (figure 5). The former defines both the amount of carbon, which must be oxidized, and the height of the inlet/outlet channels through which oxidation and evacuation of the resulting $\mathrm{CO} / \mathrm{CO}_{2}$ takes place. On the other hand, the latter one only influences oxidation and degassing.

The properties of the pastes are determined using thermogravimetric analysis (TGA), viscosimetry and sedimentation observation. The ideal paste for future applications is proposed in light of the obtained results. On the other hand, open porosity elimination temperature of LTCC is qualitatively determined by placing LTCC substrates, which are fired at different temperatures and heating rates, into a specially developed closed chamber that is integrated with a pressure sensor. Membranes, which are fabricated in light of these findings, are finally characterized by using scanning electron microscopy (SEM), surface profiler and a displacement detection system, respectively.

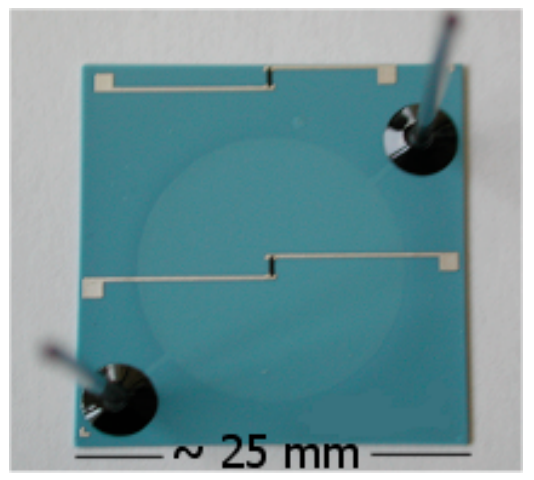

Figure 3. Membrane completed with gluing inlet and outlet ports and post-firing thick-film components.

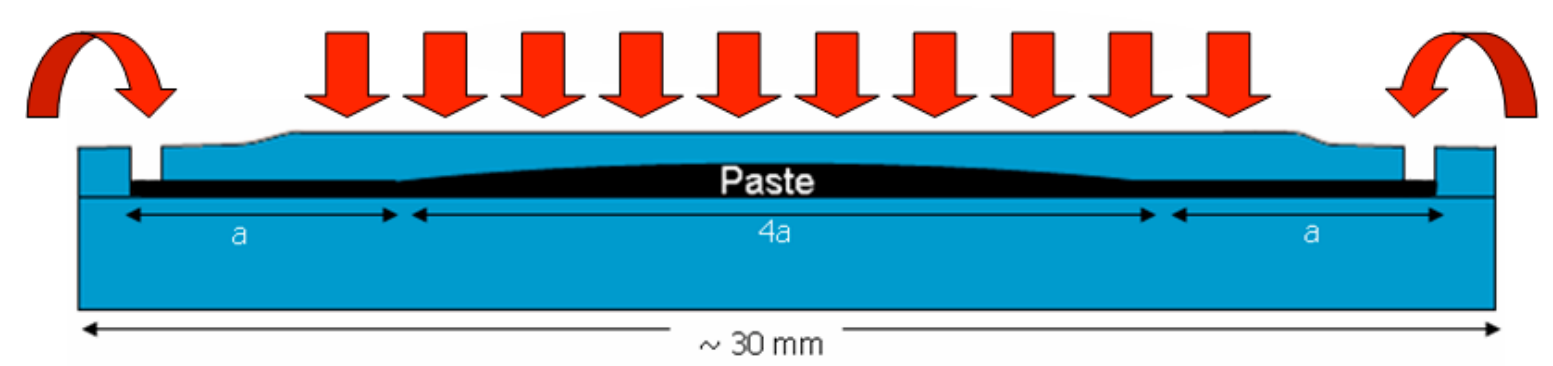

Figure 4. Oxidation of paste by air (shown by red arrows) occurs mostly through porous LTCC according to the approximate dimensions shown in the sketch of the membrane profile. 


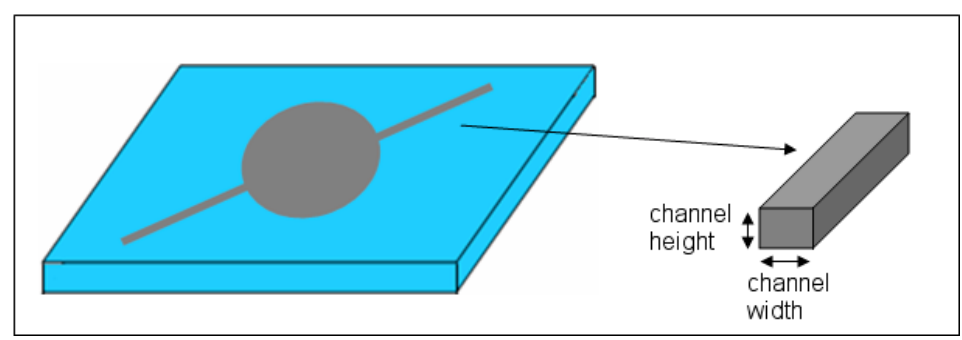

Figure 5. Details of the channel (once it is completed with lamination of the top layer): width and height is determined by the layout and the screen, respectively.

\section{Experimental details}

We used two different graphite powders: the finer one with a particle size $\left(\mathrm{d}_{50}\right)$ of $15.3 \mu \mathrm{m}$ (TIMREX KS5-25) and the coarser one with $27.0 \mu \mathrm{m}$ (TIMREX KS5-44). In this study, we did not work with much finer particles (i.e. $2 \mu \mathrm{m}$ ), since it is reported that these pastes have not provided sufficient spacing for the cavities due to fast oxidation [18]. Selected powders were individually blended with a mixture of organic vehicle that is composed of binder, solvent and dispersant (further details of the used materials and descriptions in [18]).

The number of raw materials and the difficulty of estimating their effects on final paste properties directed us to using design of experiments (DoE). By this approach, the experiments are designed in a way that the sole effects of parameters plus their interactions are considered and evaluated, yielding a complete understanding of the phenomena under investigation [20]. However, in this study, we used this method to determine the necessary number of experiments and check the effects of constituents on the pastes' properties qualitatively.

We determined five factors, which were estimated to have an influence on the pastes produced: particle size of graphite, weight percentage of graphite, binder (ethyl cellulose), solvent (terpineol) and dispersant (acetyl acetone), respectively. Among those, we selected the first three parameters as the independent factors of our experiments, while the other two (solvent and dispersant amounts) as the dependent variables determined by the following relations:

$$
\begin{aligned}
& G+B+S+D=100 \\
& D \approx 1 / 5 \times G
\end{aligned}
$$

where G, B, S and D stand for graphite, binder, solvent and dispersant ratios of the paste by weight percentage, yielding a total of $100 \%$. This gives an experimental design with three factors and two responses (variants) per factor yielding eight experiments (table 1). The ranges of the factors and equation (2) are determined according to our preliminary findings in optimizing viscosity and miscibility of pastes and recipes used in slurry preparation for tape casting $[21,22]$. The pastes (as shown in table 1) were prepared in random order to reduce the effects of environmental conditions on the experiments. The batches were $15 \mathrm{~g}$ for each paste, and table 2 shows the exact experimental order carried and the compositions used. The basic procedure followed can be summarized as

- dissolving binder in solvent at $80^{\circ} \mathrm{C}$,

- adding the graphite at small quantities over the mixture (accompanied by addition of dispersant),

- blending the overall mixture and transferring it over the three-roll mill and

- $\quad$ mixing the paste for a total of $30 \mathrm{~min}$, recovering and transferring into plastic boxes. 
At the end of processing, material losses were found in the $18-24 \%$ (by weight) range. It is estimated that the losses occurred mainly during the recovery from the three-roll mill.

The effect of heating rate on the oxidation kinetics of the graphite powder, which is selected from the previous study (TIMREX KS5-25), and the LTCC open-pore elimination is studied at 2, 5 and $8^{\circ} \mathrm{C} / \mathrm{min}$. The oxidation process is controlled using a TGA-SDTA system (Mettler Toledo TGASDTA 851e), which can perform single differential thermal analysis (SDTA), in addition to TGA. This provides a better interpretation of the nature of the process, as it gives information on the enthalpy of the process [23].

The viscosity of pastes was measured using a cup and cone type, controlled stress rheometer (Bohlen Reologi). The samples were placed between the upper cone ( $4^{\circ}$ inclination) and the fixed lower plate (40 mm diameter), following calibration with standard viscosity oils, which yielded an error of 3\%. The viscosity values upon applied shear stress were accepted and recorded with the sole condition that they remained in the reliable measuring range that is defined by the viscosity shear rate - shear stress diagram [24].

Table 1. Design of experiments.

\begin{tabular}{cccccc}
\hline Paste & $\mathrm{G}^{-} \mathrm{d}_{50}{ }^{\mathrm{a}}$ & $\mathrm{G}^{\mathrm{b}}$ & $\mathrm{B}^{\mathrm{b}}$ & $\mathrm{D}^{\mathrm{b}}=1 / 5 \times \mathrm{G}^{\mathrm{b}}$ & $\mathrm{S}^{\mathrm{b}} \rightarrow$ rest \\
\hline KS5-25-1 & 15.3 & 20 & 3 & 4 & 73 \\
KS5-25-2 & 15.3 & 20 & 5 & 4 & 71 \\
KS5-25-3 & 15.3 & 35 & 3 & 7 & 55 \\
KS5-25-4 & 15.3 & 35 & 5 & 7 & 53 \\
KS5-44-1 & 27.0 & 20 & 3 & 4 & 73 \\
KS5-44-2 & 27.0 & 20 & 5 & 4 & 71 \\
KS5-44-3 & 27.0 & 35 & 3 & 7 & 55 \\
KS5-44-4 & 27.0 & 35 & 5 & 7 & 53 \\
\hline
\end{tabular}

${ }^{a}$ Graphite particle size in $\mu \mathrm{m}$.

${ }^{\mathrm{b}}$ Percentages of ingredients (by weight) given in equations (1) and (2).

Table 2. Order of experiments and compositions of materials used.

\begin{tabular}{ccccccc}
\hline Paste & Paste code & $\mathrm{G}-\mathrm{d}_{50}{ }^{\mathrm{a}}$ & $\mathrm{G}^{\mathrm{c}}$ & $\mathrm{B}^{\mathrm{c}}$ & $\mathrm{D}^{\mathrm{c}}$ & $\mathrm{S}^{\mathrm{c}}$ \\
\hline KS5-44-2 & P1 & 27.0 & 3.00 & 0.75 & 0.60 & 10.65 \\
KS5-25-3 & P2 & 15.3 & 5.25 & 0.45 & 1.05 & 8.25 \\
KS5-44-4 & P3 & 27.0 & 5.25 & 0.75 & 1.05 & 7.95 \\
KS5-25-1 & P4 & 15.3 & 3.00 & 0.45 & 0.60 & 10.95 \\
KS5-44-3 & P5 & 27.0 & 5.25 & 0.45 & 1.05 & 8.25 \\
KS5-25-4 & P6 & 15.3 & 5.25 & 0.75 & 1.05 & 7.95 \\
KS5-44-1 & P7 & 27.0 & 3.00 & 0.45 & 0.60 & 10.95 \\
KS5-25-2 & P8 & 15.3 & 3.00 & 0.75 & 0.60 & 10.65 \\
\hline
\end{tabular}

${ }^{\mathrm{a}}$ Graphite particle size in $\mu \mathrm{m}$.

${ }^{\mathrm{c}}$ Weight (g) of ingredients given in equations (1) and (2). 
The effect of heating rate on LTCC open pore elimination, on the other hand, is analyzed by using a previously developed [18] closed-chamber system (figure 6). LTCC sheets, which are fired in the $750-810^{\circ} \mathrm{C}$ range and varying in thickness $(254$ and $50 \mu \mathrm{m}$ thick tapes from DuPont 951-AX and 951-C2 series, respectively), are used in this analysis [25]. Response of the instrument for a porous substrate is shown in figure 7, where one can see two peaks indicating pressure application and release immediately after due to porosity. The criterion for closure of open porosity in this study is for the pressure drop, to remain below $10 \%$ of the initial overpressure in a time interval of $900 \mathrm{~s}$.

Membranes are fabricated from thick and thin LTCC sheets, which are used for the base and the membrane layer, respectively. The optimized graphite paste, which exhibits necessary features for screen printing and processing, is screen printed on the thick LTCC sheet according to the layout shown in figure $1 \mathrm{~b}$. It is dried in the ambient conditions and at $120^{\circ} \mathrm{C}$, each for $10 \mathrm{~min}$. The printed thickness is measured using a surface profiler (UBM), which operates by laser reflection. The thickness varies as a function of the screen used for printing, which is designated by two numbers: number of wires per inch $(1 \mathrm{inch}=25.4 \mathrm{~mm})$ and emulsion thickness in $\mu \mathrm{m}$ [26-28]. The screen with coarser mesh and thicker emulsion (i.e. 165/80 for this study) permits increased passage of paste, yielding a higher printed thickness, around $70 \mu \mathrm{m}$, whereas the screen with finer mesh and finer emulsion (325/40) results in a thickness of about $27 \mu \mathrm{m}$. This data represent the average of a wide range of values, where the screen with coarser mesh provides a better reproducibility of printed thickness.

Following this step, the printed LTCC sheet is collated with two other thick layers from the bottom (254 $\mu \mathrm{m}$ thick Du Pont 951-AX) and one $50 \mu \mathrm{m}$ thick LTCC sheet (Du Pont 951-C2) from the top, which is actually the membrane (figure 8). Compared to our previous studies, the base thickness was considerably increased in order to enhance its mechanical stability and stiffness, thus providing cleaner boundary conditions for the membrane. This structure is laminated at $25 \mathrm{MPa}$ with a uniaxial press having a heating plate that is kept at $70^{\circ} \mathrm{C}$ during pressing. The laminated piece is then fired in an LTCC oven (ATV-601) according to a two step firing profile with two dwell temperatures: about $440^{\circ} \mathrm{C}$ for LTCC organics burnout $(2 \mathrm{~h})$ and $875^{\circ} \mathrm{C}$ for densification of LTCC (25 min) according to manufacturer's processing guidelines [25]. For the graphite paste, $440^{\circ} \mathrm{C}$ conveniently lies above the organics vehicle burnout $\left(\sim 330^{\circ} \mathrm{C}\right)$ and well below the onset of graphite oxidation $\left(\sim 600^{\circ} \mathrm{C}\right)$, which will be presented in the next part. Finally, the inlet and outlet tubes are glued to complete the fluidic channel and characterize the membrane displacement (figure 3 ).

The details of the experimental conditions in terms of heating rate, screen type and channel width are presented in table 3. The heating rates are selected as $2.50,2.00$ and $1.75^{\circ} \mathrm{C} / \mathrm{min}$, which are relatively lower rate than those used in the previous paper. This is basically due to the need to reduce membrane swelling, which occurs at increased heating rates and membrane diameters [18, 25]. In addition to heating rate, two parameters affecting the membrane shape were varied: printed thickness (see above) and channel width $(200$ or $400 \mu \mathrm{m})$. Increasing printed thickness has two effects: it increases the amount of enclosed graphite in the membrane, but it also allows better burnout due to increased channel height. Channel width, on the other hand, has a more unambiguous effect, affecting only the burnout through assorted change in channel cross-section.

The cavity thickness profile (membrane interior region) is analyzed in the $18 \mathrm{~mm}$ long, edge-toedge cross-sectional area by SEM. Swelling of the membranes, on the other hand, is detected by the surface profiler, which is also used for printed thickness measurement. For the membrane displacement, the channels are connected to the source, the pressure of which is regulated by a Druck DPI 520 pressure controller. The displacement is detected by a laser displacement meter (Keyence LC series), operating at the $5-450 \mu \mathrm{m}$ range. The pressure range, depending on the swelling extent, is selected between -200 and 100 mbar, with three or four half cycle runs (one half cycle is one complete run from -200 to 100 mbar or back). 


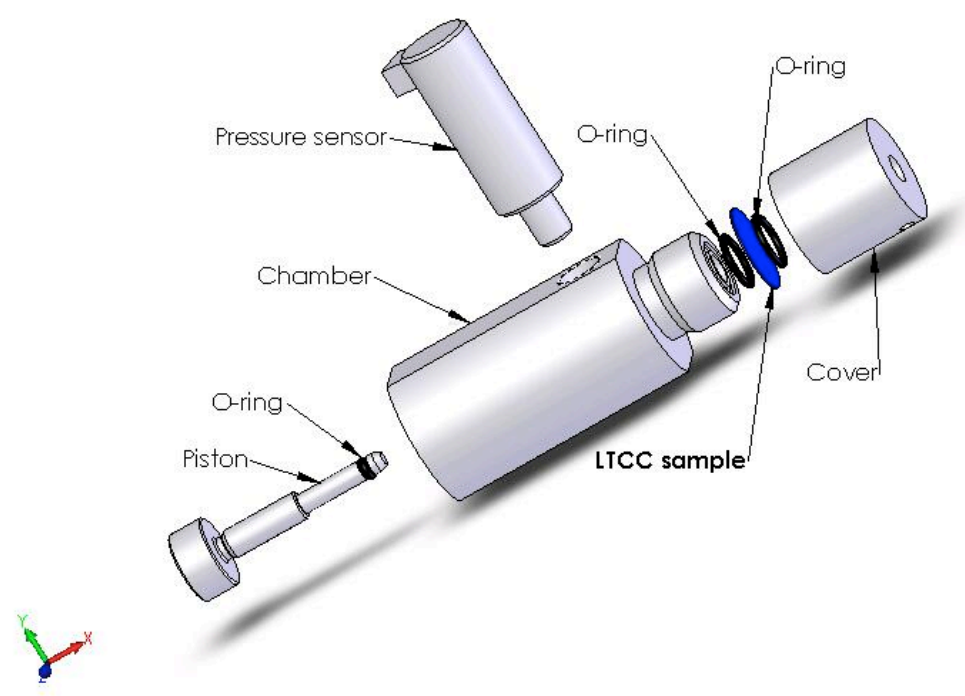

Figure 6. Closed-chamber system for detection of LTCC open-porosity elimination temperature.

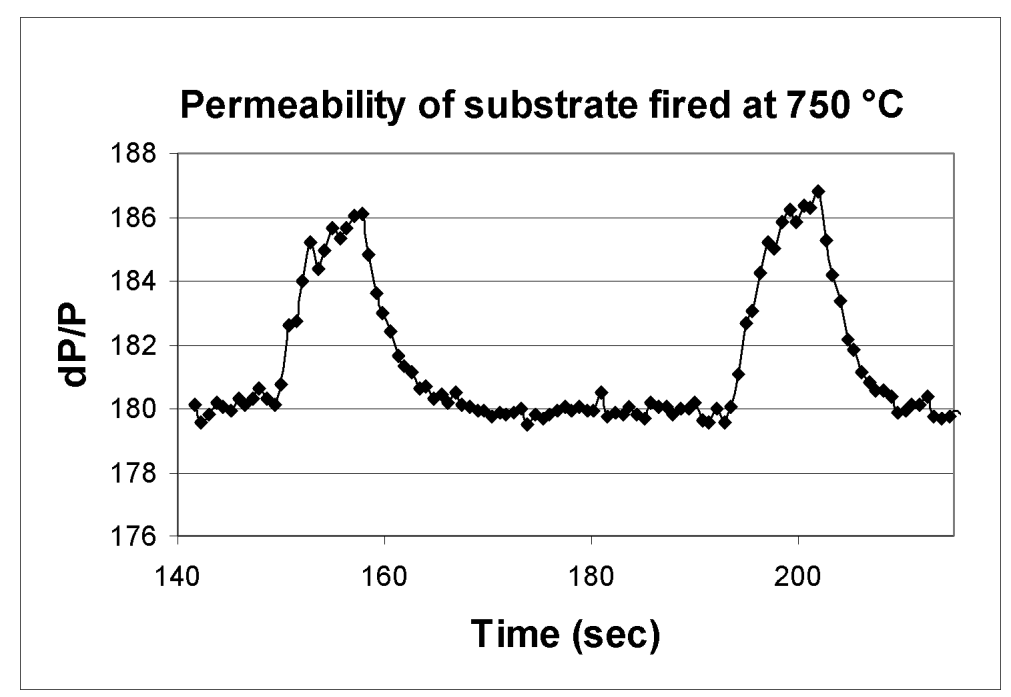

Figure 7. Effect of piston, which is closed at two instants are observed as a rapid increase and consecutive decrease of pressure, due to porous substrate fired at $750^{\circ} \mathrm{C}$ (DuPont 951-AX).

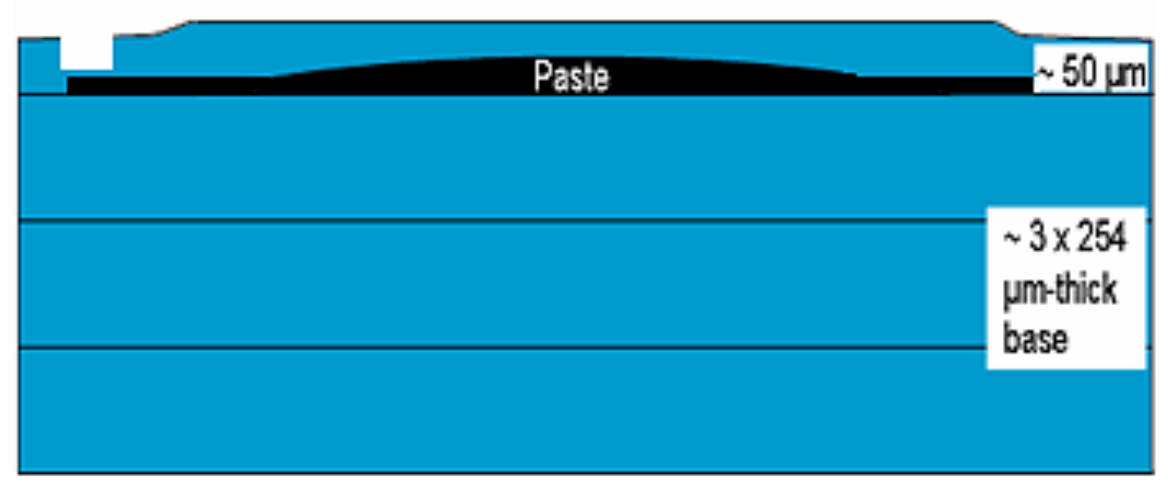

Figure 8. Layers of the membrane. 
Table 3. Experiments to study effects of selected processing parameters.

\begin{tabular}{cccc}
\hline Series $18 \mathrm{~mm}$ & $\mathrm{HR}\left({ }^{\circ} \mathrm{C} / \mathrm{m}\right)$ & Screen (mesh/emulsion) & Channel width $(\mathrm{mm})$ \\
\hline S1 & 2.50 & $325 / 40$ & 0.20 \\
S2 & 2.50 & $325 / 40$ & 0.40 \\
S3 & 2.50 & $165 / 80$ & 0.20 \\
S4 & 2.50 & $165 / 80$ & 0.40 \\
S5 & 2.00 & $325 / 40$ & 0.20 \\
S6 & 2.00 & $325 / 40$ & 0.40 \\
S7 & 2.00 & $165 / 80$ & 0.20 \\
S8 & 2.00 & $165 / 80$ & 0.40 \\
S9 & 1.75 & $325 / 40$ & 0.20 \\
S10 & 1.75 & $325 / 40$ & 0.40 \\
S11 & 1.75 & $165 / 80$ & 0.20 \\
S12 & 1.75 & $165 / 80$ & 0.40 \\
\hline
\end{tabular}

\section{Results}

\subsection{Selection of paste and determination of LTCC open-porosity elimination temperature}

Figure 9 gives the corresponding TGA results in terms of remaining weight versus temperature. The analysis was performed by heating about $5 \mathrm{mg}$ of paste, which is transferred to the alumina crucible of the TGA instrument, at a rate of $2^{\circ} \mathrm{C} / \mathrm{min}$. It is seen that the organic vehicle is fully consumed by $330^{\circ} \mathrm{C}$, and the onset of graphite oxidation temperature is around $600^{\circ} \mathrm{C}$. This yields a very comfortable processing window for preparation of devices given typical LTCC binder burnout temperatures of about $450^{\circ} \mathrm{C}$ [18]. The remaining weight fraction between these temperatures agrees well with the relative amount of graphite in the paste.

Table 4 shows the applied shear stress range and the instant viscosities at 10 or $100 \mathrm{~Pa}$, depending on the rheological properties of pastes. In the case of low solid (graphite) content, the pastes possessed low viscosities and instant viscosity was measured using $10 \mathrm{~Pa}$. In a similar manner, viscosity of pastes with higher solids loading was measured at $100 \mathrm{~Pa}$. Moreover, the extent of sedimentation is also presented in table 4.

The pastes were also visually checked to determine the extent of sedimentation one month after processing (table 4). This simple process provides a quick idea on the quality of dispersion of particles in the paste, thus giving information on the stability of the produced paste in long terms. It was observed that pastes with higher viscosities showed almost no sedimentation, whereas graphite in the others precipitated in the paste.

The results summarized in table 4 suggest that instant viscosity and extent of sedimentation, which are the responses of the experimental design, cannot be used in order to analyze the influence of factors quantitatively. This is due to different test conditions used for the responses; i.e. instant viscosity of pastes measured at two different stresses due to different rheology of pastes, which ruled out the requirement (orthogonality) for quantitative description. 


\section{TGA Comparison of Pastes}

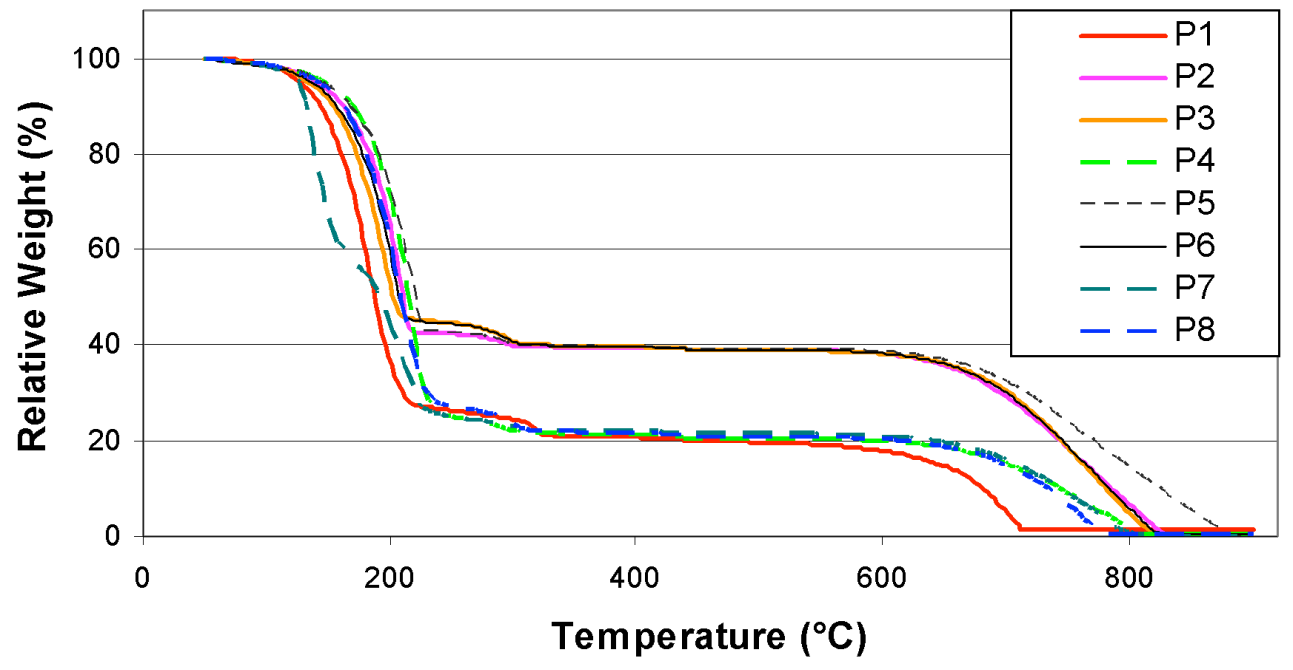

Figure 9. TGA curves $\left(2^{\circ} \mathrm{C} / \mathrm{min}\right.$, ca. $\left.5 \mathrm{mg}\right)$ of different pastes.

Table 4. Overall Results.

\begin{tabular}{ccccccc}
\hline $\begin{array}{c}\text { Paste } \\
\text { code }\end{array}$ & $\mathrm{G}^{-\mathrm{d}_{50}{ }^{\mathrm{a}}}$ & $\mathrm{G}^{\mathrm{b}}$ & $\mathrm{B}^{\mathrm{b}}$ & $\mathrm{S}^{\mathrm{b}}$ & $\begin{array}{c}\text { Instant viscosity }(\mathrm{Pa} \cdot \mathrm{s}) \\
\text { at } 10^{\mathrm{c}} \& 100^{\mathrm{d}} \mathrm{Pa}\end{array}$ & $\begin{array}{c}\text { Extent of } \\
\text { sedimentation }\end{array}$ \\
\hline P6 & 15.3 & 5.25 & 0.75 & 7.95 & 1055 & None \\
P3 & 27 & 5.25 & 0.75 & 7.95 & 721 & None \\
P2 & 15.3 & 5.25 & 0.45 & 8.25 & 442 & None \\
P5 & 27 & 5.25 & 0.45 & 8.25 & 123 & None \\
P8 & 15.3 & 3.00 & 0.75 & 10.65 & 18.5 & Extreme \\
P1 & 27 & 3.00 & 0.75 & 10.65 & 13.4 & Extreme \\
P7 & 27 & 3.00 & 0.45 & 10.95 & 4.1 & Extreme \\
P4 & 15.3 & 3.00 & 0.45 & 10.95 & 3.7 & Extreme \\
\hline
\end{tabular}

\footnotetext{
${ }^{a}$ Graphite particle size in $\mu \mathrm{m}$.

${ }^{\mathrm{b}}$ Weight (g) of ingredients given in equations (1) and (2).

${ }^{\mathrm{c}, \mathrm{d}}$ Instant viscosity measured at $10 \mathrm{~Pa}$ (text written in italics) and $100 \mathrm{~Pa}$, respectively.
} 
According to the factors and ranges selected, $35 \%$ by weight of graphite is estimated to be the upper limit of the graphite-based sacrificial paste so far. In addition to this, P2, P3 and P5 have the best compatibility with screen printing and show resistance to sedimentation (stable) so that they are considered to be the candidate pastes for future applications, with P2, being preferred (about $20 \%$ volume graphite) as it lies in the middle of the optimal range.

The oxidation kinetics of the graphite powder as a function of heating rate and the development of open porosity closure on a $50 \mu \mathrm{m}$ thick LTCC tape that is heated at $2{ }^{\circ} \mathrm{C} / \mathrm{min}$ are shown in figures 10 and 11, respectively. As expected, slower heating rate permits sufficient time for the oxidation reaction, thus resulting in full burnout at low temperature. On the contrary, faster heating rate $\left(8^{\circ} \mathrm{C} / \mathrm{min}\right)$ delays full oxidation to about the maximum temperature used so far in this study $\left(900^{\circ} \mathrm{C}\right)$, far above the open pore elimination temperature of LTCC $\left(\leq 800^{\circ} \mathrm{C}\right)$. The open porosity closure temperature for the other samples is determined through the same procedure, and the results are compiled in table 5. Despite the shift to higher temperatures, which is observed at faster heating rates, open porosity elimination is mainly confined to a narrow temperature range. This indicates a reduced sensitivity of LTCC densification process to heating rate compared to the graphite oxidation, which occurs over a wider temperature range.
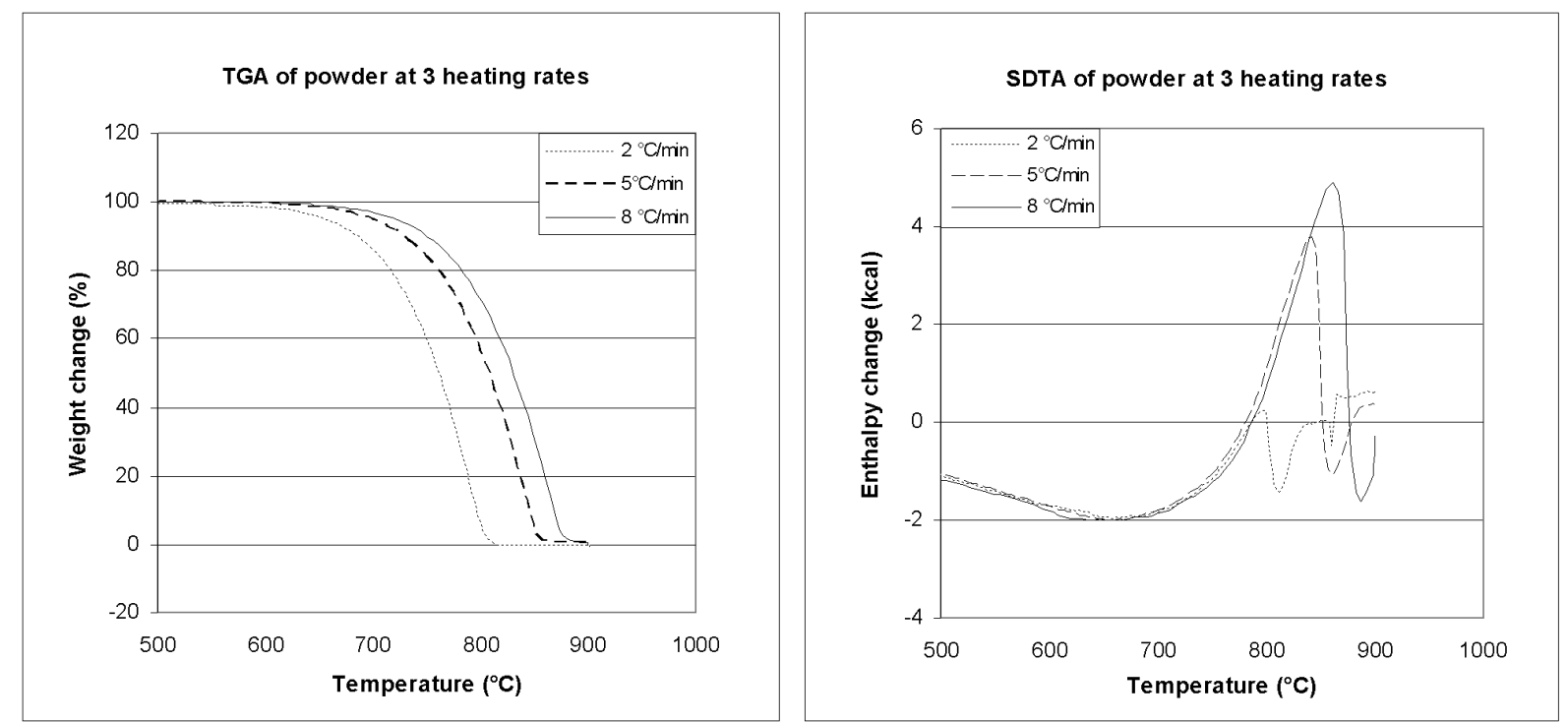

Figure 10. TGA (left) and SDTA analysis of powder heated at 2,5 and $8{ }^{\circ} \mathrm{C} / \mathrm{min}$ TGA shows the mass losses and SDTA indicates the enthalpy of the reactions.

Table 5. Heating rate versus LTCC pore elimination temperature $\left( \pm 2.5^{\circ} \mathrm{C}\right)$.

\begin{tabular}{cccc}
\hline & \multicolumn{3}{c}{ Heating rate $\left({ }^{\circ} \mathrm{C} / \mathrm{min}\right)$} \\
LTCC $(\mu \mathrm{m})$ & 2 & 5 & 8 \\
\hline 50 & 785 & 785 & 795 \\
254 & 765 & 765 & 775 \\
\hline
\end{tabular}




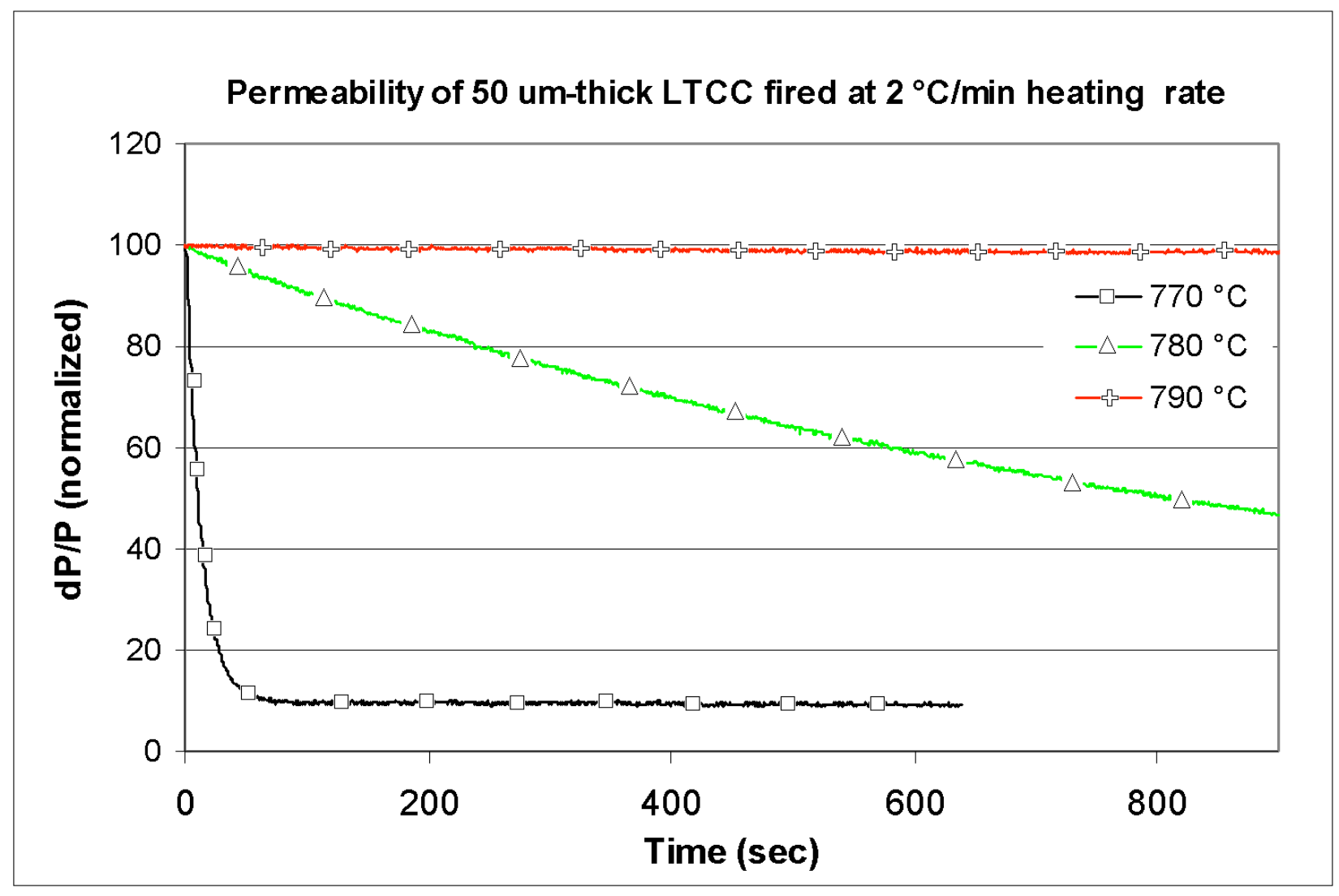

Figure 11. Evolution of open porosity for a $50 \mu \mathrm{m}$-thick $\mathrm{LTCC}$ tape that is heated at $2^{\circ} \mathrm{C} / \mathrm{min}$ rate.

\subsection{Fabrication and characterization of pressure sensitive LTCC membranes}

3.2.1. Thickness of cavity (membrane spacing). The cavities formed by the removal of the selected paste (P2) and as a function of heating rate are schematically depicted in figure 12 . The reduced spacing at minimum heating rate, apart from other processing parameters, is ascribed to early-stage paste oxidation. Moreover the edges of the membranes tend to fuse to the base due to glass softening in LTCC induced by laser cutting of samples for SEM analysis (figure 13). These two effects increase the extent of collation for membranes those fired at lower rates, reducing their detectable length and thickness. This decreases the apparent diameter especially for membranes fired at lower heating rates.

Figure 14 shows the membrane spacing profiles for the representative membranes selected from each experimental group. Typical spacing values are also presented in table 6, as an average of 5-6 membranes per group. Although not shown here, it would be useful to note that membranes fired at lower heating rates exhibited poor reproducibility in terms of cavity spacing. For higher heating rates, on the other hand, screens providing higher paste deposition (165/80) and wider channels $(0.40 \mathrm{~mm})$ resulted in membranes with reproducible results. 


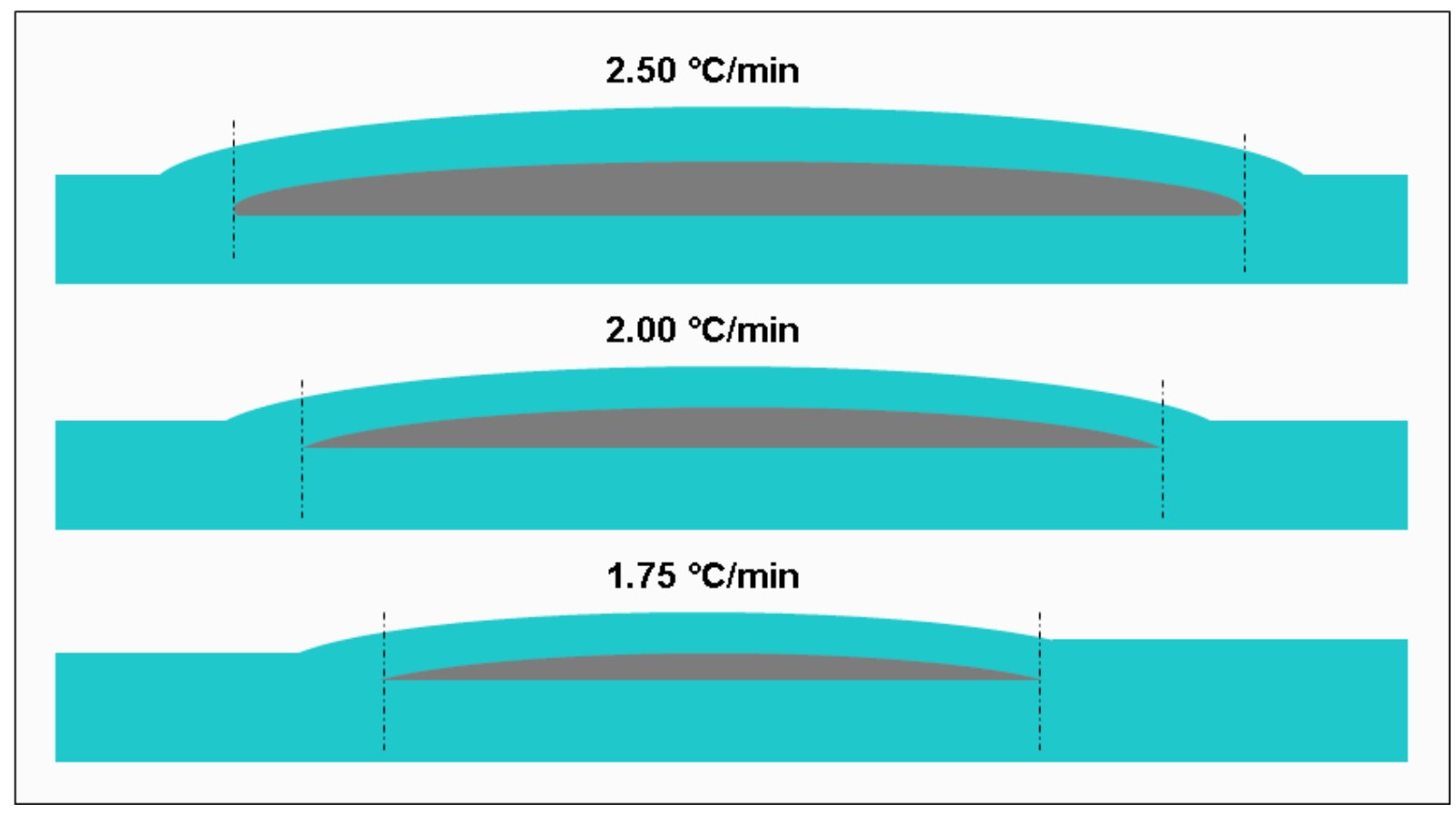

Figure 12. Qualitative description of membranes with identical screen and channel width, at high heating rates $\left(2\right.$ and $\left.2.5^{\circ} \mathrm{C} / \mathrm{min}\right)$. The regions out of the dashes are apparently closed.

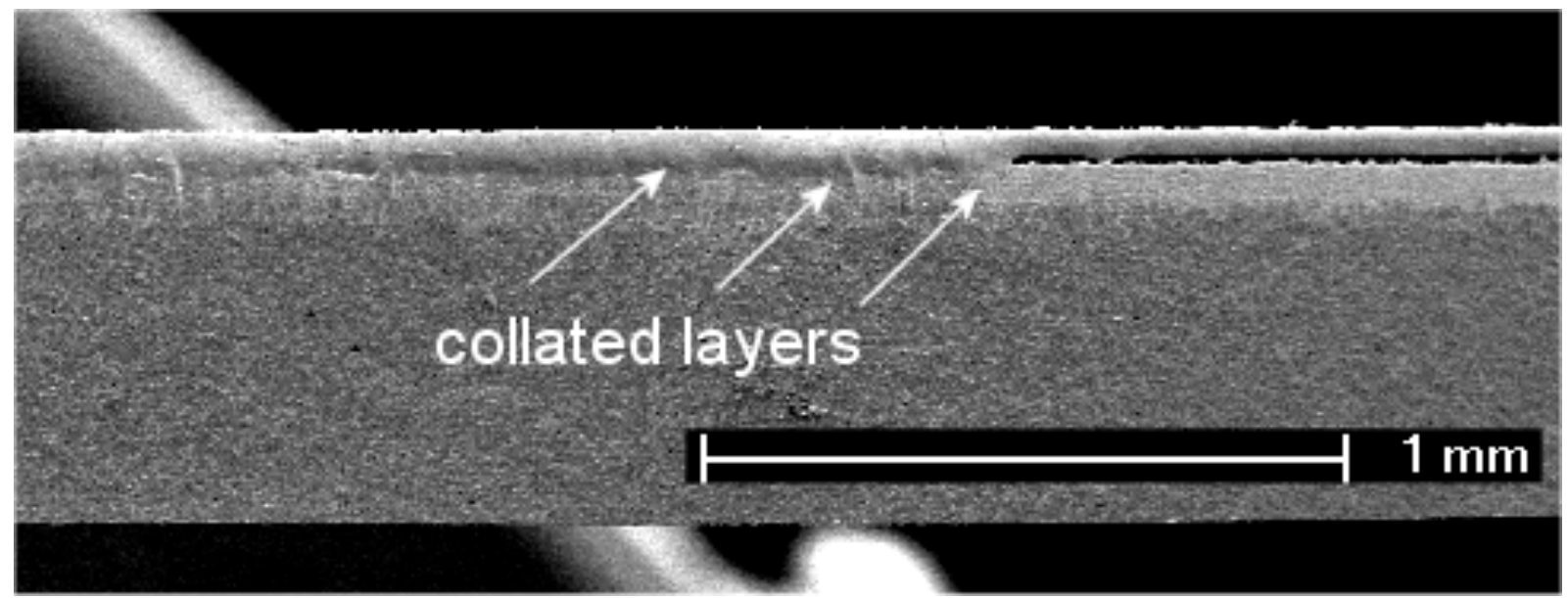

Figure 13. SEM image showing the increased extent of collation of layers at the edge (arrows) due to lowest heating rate and laser cutting.

Table 6. Results of the membrane spacing analysis.

\begin{tabular}{lccc}
\hline & \multicolumn{3}{c}{ Heating rates $\left({ }^{\circ} \mathrm{C} / \mathrm{min}\right)$} \\
Screen-channel $(\mathrm{mm})$ & 2.50 & 2.00 & 1.75 \\
\hline $325 / 40-0.20$ & Representative spacing at the center of the membrane $(\mu \mathrm{m})$ \\
$325 / 40-0.40$ & 140 & 35 & 24 \\
$165 / 80-0.20$ & 50 & 32 & 27 \\
$165 / 80-0.40$ & 57 & 31 & 21 \\
\hline
\end{tabular}



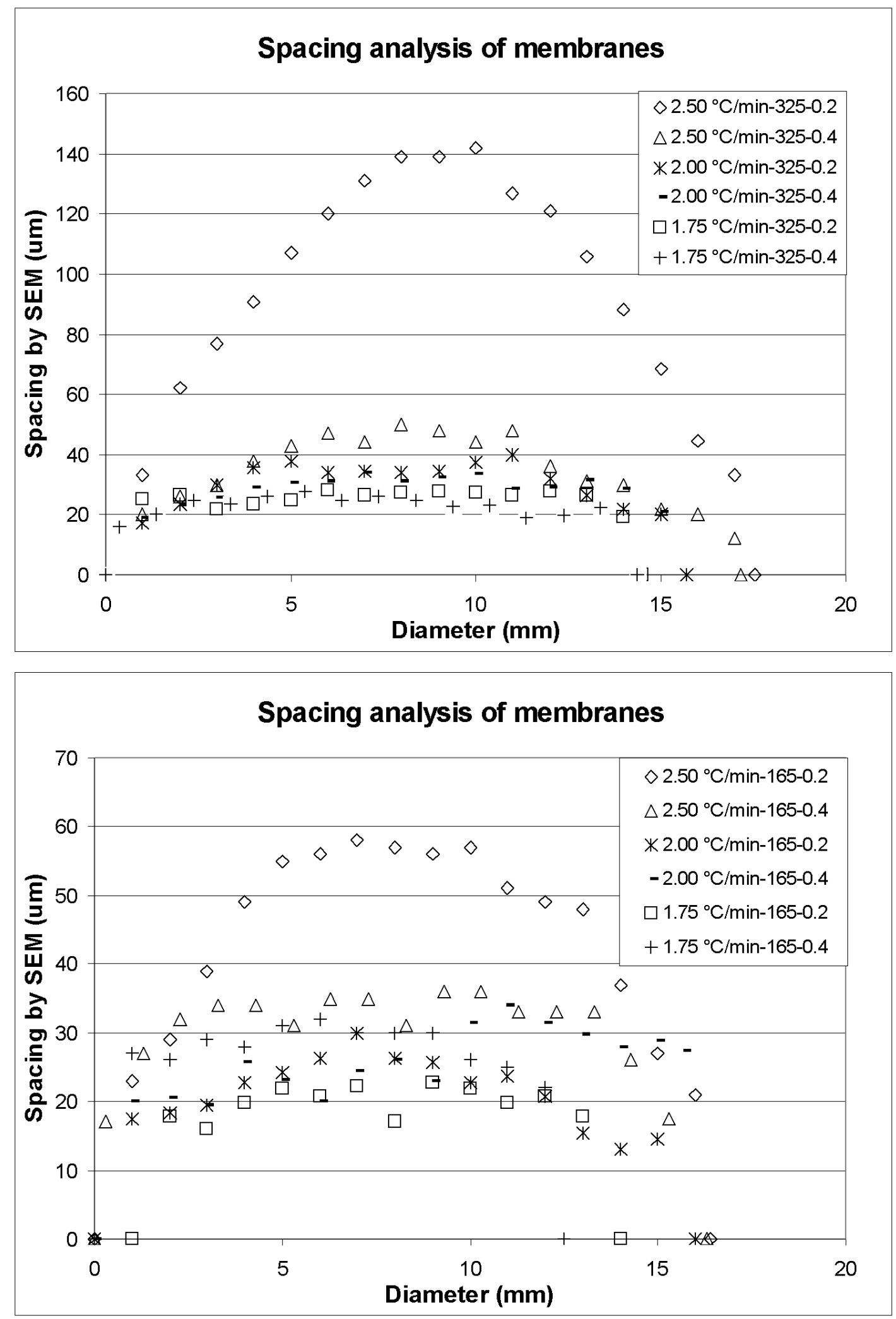

Figure 14. Membrane spacing in terms of heating rate for membranes those prepared with (a) $325 / 40$ (top) and (b) 165/20 screens. Note the different scale in both figures. 
3.2.2. Membrane displacement and swelling. In light of previous observations, we used the membranes fired at $2.50^{\circ} \mathrm{C} / \mathrm{min}$ in order to analyze the effect of screen and channel width on functional properties of membranes.

The most interesting feature of samples is found to be the hysteretic behavior of membrane displacement as a function of pressure. The dependence and extent of hysteresis, therefore, is studied in order to determine the relation between the processing conditions and properties of fabricated membranes. The procedure of hysteresis analysis can be listed as follows:

1. The data, which consist of displacement values as a function of pressure, are represented by two terms: origin and the sign. The former one is defined as the displacement value that is equal to zero $(\mathrm{z}=0)$, when the membrane touches the base, whereas the latter is positive for increasing membrane-base distance (figure 15).

2. To determine the hysteresis that is representative for each membrane, the derivative of displacement as a function of pressure $(\mathrm{d} z / \mathrm{d} P)$ is calculated to find switching pressures defined as the positions of the peaks in $\mathrm{d} z / \mathrm{d} P$ (figure 16a). The procedure corresponding displacements are then taken at the center of the switching range (figure 16b). For this, the data are treated as follows:

$P: \quad$ average pressure over 12 points (about $\pm 2 \mathrm{mbar}$, three values $/ \mathrm{mbar}$ ),

$\mathrm{d} z / \mathrm{d} P$ : slope of the least square linear regression fit of $z$ versus $P$, over the same 12 points,

$P^{+}: \quad$ upper switching pressure $=$ peak of $\mathrm{d} z / \mathrm{d} P$ with increasing $P$,

$P^{-}: \quad$ lower switching pressure $=$ peak of $\mathrm{d} z / \mathrm{d} P$ with decreasing $P$ (figure $16 \mathrm{a}$ ),

$\Delta P: \quad$ pressure hysteresis, defined as $\Delta P=P^{+}-P^{-}$,

$P_{\mathrm{c}}: \quad$ center of pressure hysteresis: $P_{\mathrm{c}}=\left(P^{+}-P^{-}\right) / 2$,

$z^{+}: \quad$ displacement at $P_{\mathrm{c}}$ with decreasing $P$,

$z^{-}$: $\quad$ displacement at $P_{\mathrm{c}}$ with increasing $P$ (figure $16 \mathrm{~b}$ ),

$\Delta z: \quad$ displacement hysteresis, defined as $\Delta z=z^{+}-z^{-}$

The extent of hysteresis in terms of processing conditions is demonstrated in table 7 . It is seen that swollen membranes (high spacing) lead to pronounced hysteresis behavior. Moreover, screens providing increased deposition of paste (165/80) in addition to wider channels result in reduced spacing, which will be further discussed in the Conclusions section.

Table 7. Hysteresis ranges.

\begin{tabular}{cccc}
\hline Processing parameters & $\begin{array}{c}\text { Width of hysteresis } \\
\Delta P(\mathrm{mbar})\end{array}$ & $\begin{array}{c}\text { Height of hysteresis } \\
\Delta z(\mu \mathrm{m})\end{array}$ & $\begin{array}{c}\text { Spacing at the center } \\
d(\mu \mathrm{m})\end{array}$ \\
\hline $165 / 80-0.40$ & 3.8 & 36.5 & 37 \\
$165 / 80-0.20$ & 7.1 & 58.4 & 57 \\
$325 / 40-0.40$ & 24.1 & 110 & 50 \\
$325 / 40-0.20$ & 28.8 & 148.3 & 140 \\
\hline
\end{tabular}


Pressure vs Displacement

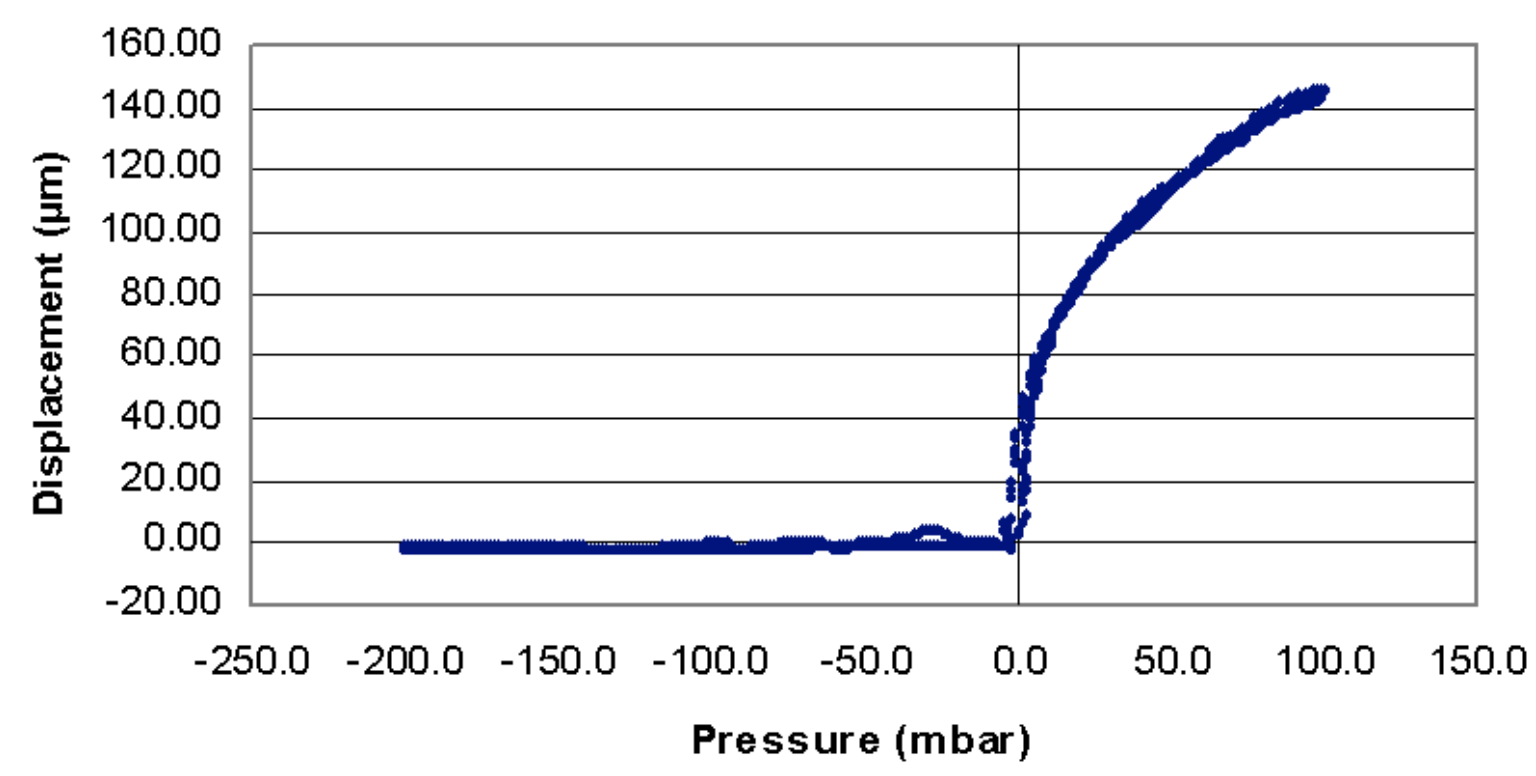

Figure 15. Displacement versus pressure (at $2.5^{\circ} \mathrm{C} / \mathrm{min}$ heating rate and using $165 / 80$ screen with $400 \mu \mathrm{m}$ wide channels)
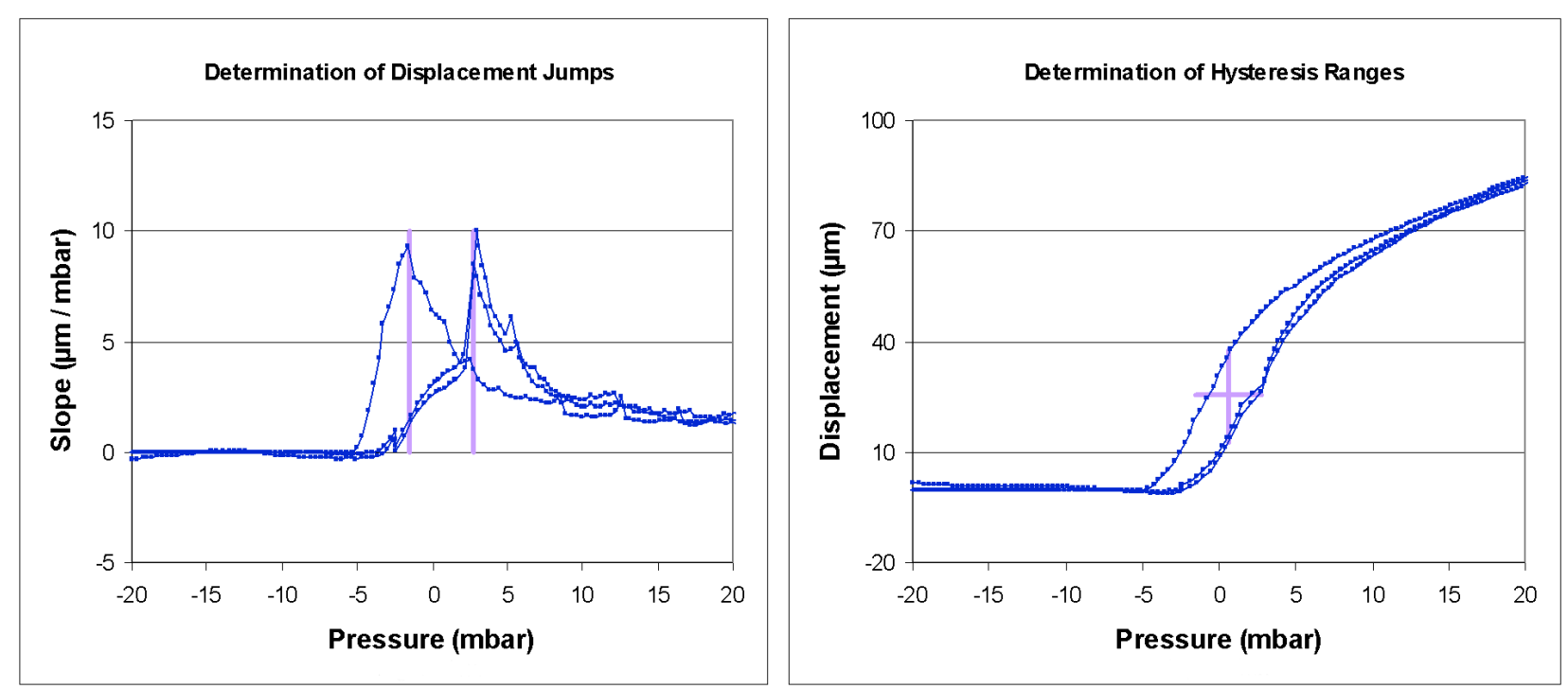

Figure 16. Determination of hysteresis parameters of a selected membrane (prepared by $165 / 20$ screen with $400 \mu \mathrm{m}$ channel width and fired at $2.5^{\circ} \mathrm{C} / \mathrm{min}$ ); (a) displacement jumps (left) and (b) hysteresis area (three half cycles: two increasing and one decreasing).

From the swelling point of view, on the other hand, membranes with wider channels fabricated from screens providing thicker paste deposition, possess reduced swelling. This indicates that the characteristics of the channels, which become the dominant mechanism of degassing upon closure of LTCC porosity, are the most important factors controlling the extent of swelling at a given heating rate. Thus, wider channels promote easy degassing. In the case of paste thickness, our results indicate that the increased channel height brought about by thicker paste more than compensates for the increased amount of carbon to oxidize. 

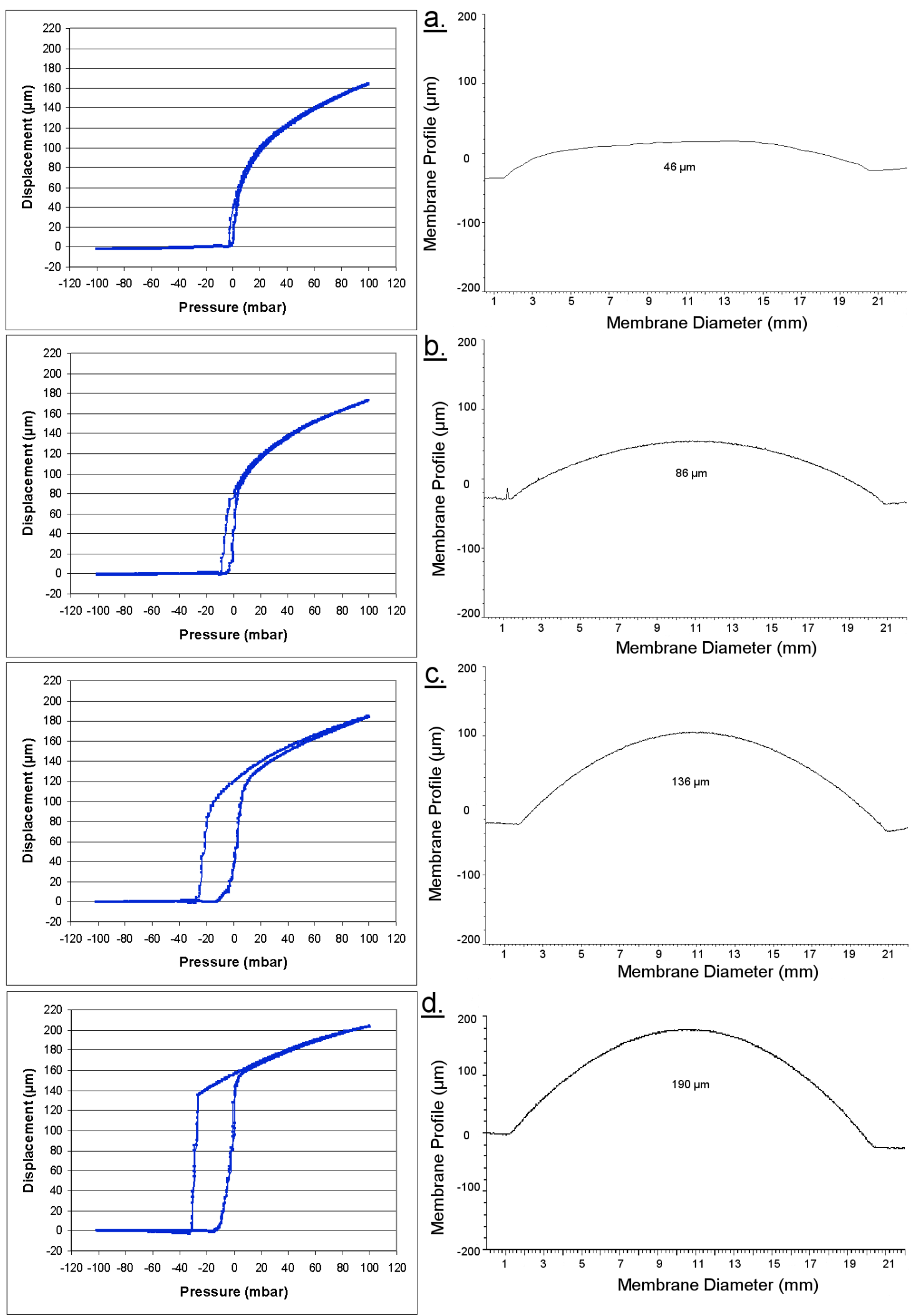

Figure 17. Displacement (left column) and surface profile of membranes fired at $2.5^{\circ} \mathrm{C} / \mathrm{min}$ in terms of screen and channel width. Screen: 165/80, channel width: 400 and $200 \mu \mathrm{m}$, respectively, (a) and (b); screen: 325/40, channel width: 400 and $200 \mu \mathrm{m}$, respectively, (c) and (d). 
The relation between the membrane displacement and swelling is demonstrated in figure 17 . It is clearly seen that the hysteresis increases with increased swelling, which is observed in membranes fabricated with narrow channels and thin paste. From a general perspective, hysteresis can originate from compressive stresses or deformation of the structure [29-31]. The former effect is thought to be less likely in our application since internal stresses are not expected considering the homogenous structure of LTCC material. Therefore, the hysteretic behavior of membrane displacement as a function of pressure is ascribed to swelling.

3.2.3. Fabricated structures. The extreme case of swelling, which occurs at relatively higher heating rates, is demonstrated in figure 18. Images shown in figure 19, on the other hand, represent membranes with smaller spacing, free of swelling or sagging. It is clearly seen that the technique is very efficient and suitable for fabrication of well-integrated LTCC structures with controlled geometry.

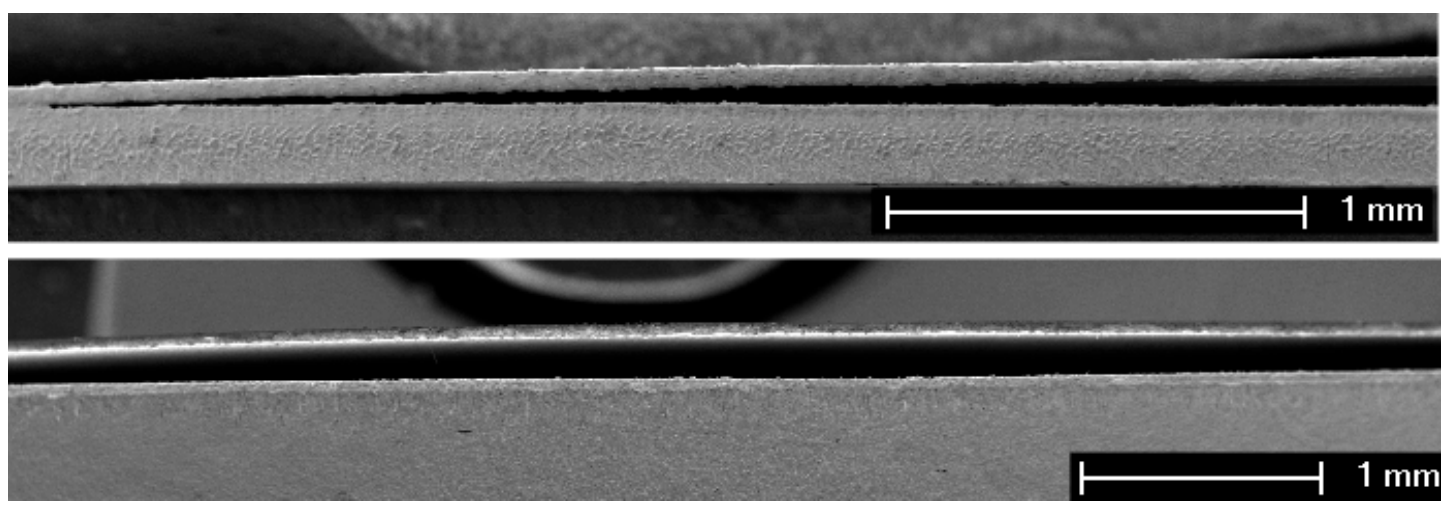

Figure 18. (a) Edge (on the top) and (b) middle section of the membranes produced by using $325 / 40$ screens $\left(200 \mu \mathrm{m}\right.$ wide channels and $2.5^{\circ} \mathrm{C} / \mathrm{min}$ heating rate).

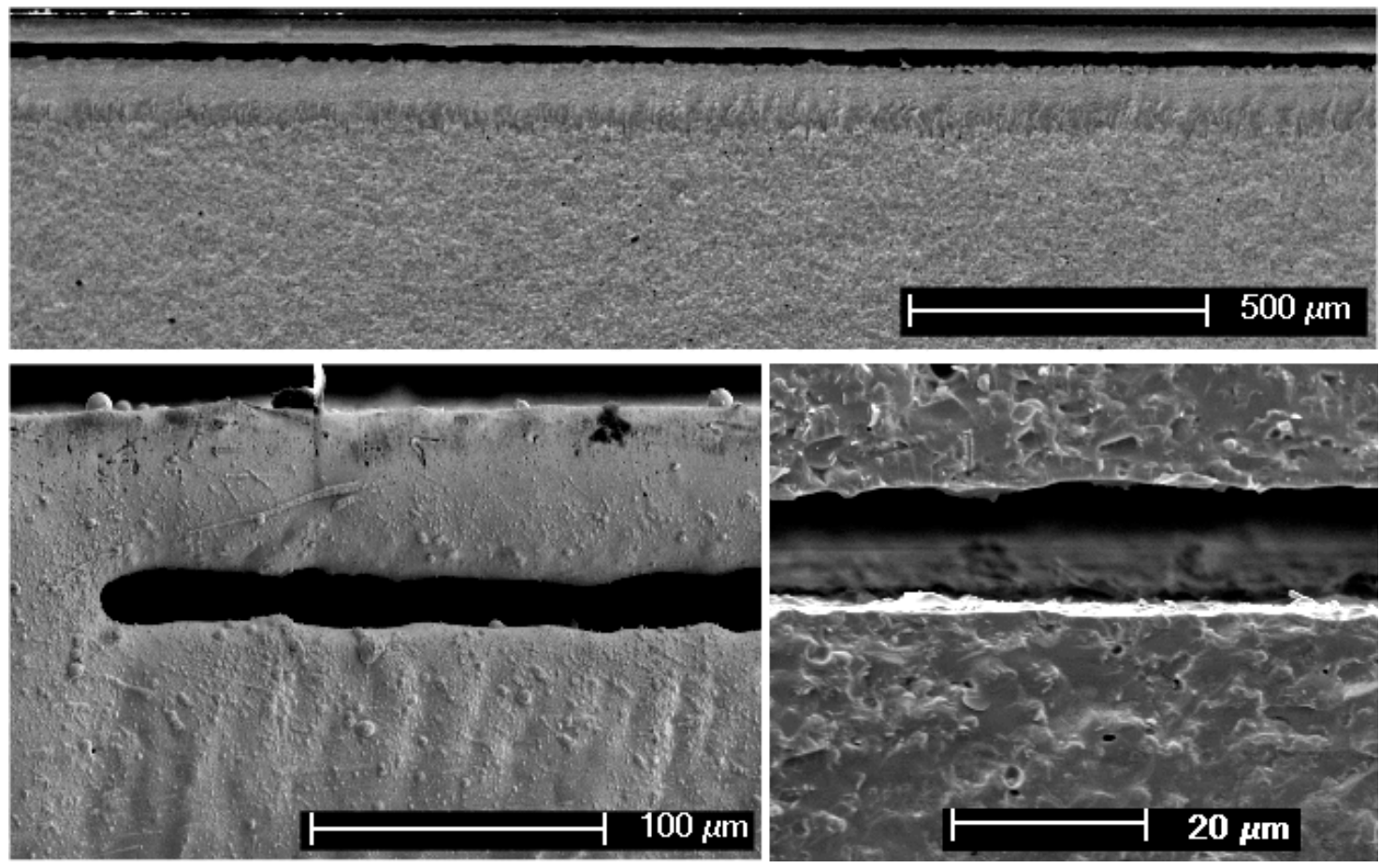

Figure 19. Well-integrated and sag-free membranes produced by using $165 / 80$ screens and $400 \mu \mathrm{m}$ wide channels $\left(1.75^{\circ} \mathrm{C} / \mathrm{min}\right.$ heating rate). 


\section{Conclusions}

Graphite-based sacrificial pastes are used efficiently to fabricate cavities in LTCC sheets. The essentials of the technique, which is dependent on the materials used and processing conditions in addition to the features of the fabricated structures, can be listed as the following:

1. Viscosity of pastes is a strong function of the solvent content, as expected. However, it is seen that for similar solvent content, the binder percentage has a stronger influence on the instant viscosity of the pastes.

2. The finer particles result in higher viscosities compared to coarser particles, except at high solvent and low binder contents (P4 and P7), where viscosity is very low.

3. Pastes with minimum viscosities were prone to extreme sedimentation. This is ascribed to precipitation of graphite particles in the solvent-excess environment, contrary to stable compositions with higher viscosity.

4. The least viscous pastes, P1, P4, P7 and P8 show excessive sedimentation and thus insufficient stability, P4 and P7 could not be screen printed, even immediately after thorough mixing. On the other extreme, P6 is too viscous, and is found to be excessively sensitive to solvent loss.

5. It has been found that the graphite powder is oxidized at $800^{\circ} \mathrm{C}$ at the lowest heating rate $\left(2{ }^{\circ} \mathrm{C} / \mathrm{min}\right)$ and this temperature is shifted to higher temperatures at increased heating rates. However, in a real structure, oxidation is likely to be further delayed by reduced access to oxygen, compared to a powder in an open crucible.

6. LTCC open-porosity elimination is found to occur in a narrow temperature range for different heating rates. Thinner LTCC tapes and higher heating rates exhibit slightly higher pore elimination temperatures.

7. In light of points 5 and 6 , it is seen that heating rate has a more pronounced effect on graphite oxidation than LTCC open pore elimination, which occurs at a narrow temperature range. Therefore, graphite burnout tends to occur before open porosity elimination in LTCC at low heating rates, and the converse is true at high rates. The exact balance also depends on LTCC thickness, and is also expected to be influenced by the particular structure of a device (presence of organics, channels and geometry for instance). Faster rates, under the same experimental conditions, lead to more swelling of the membranes.

8. Changing the channel width allows to control the degree of swelling independently of other parameters, by affecting the ease of oxidation of graphite and degassing of $\mathrm{CO} / \mathrm{CO}_{2}$.

9. The facilitation of burnout brought about by large paste thickness (higher channels) has a stronger effect than the increased amount of graphite: overall swelling is reduced. In practice, selecting large graphite thickness leads to more reproducible membrane geometries.

10. The appearance and degree of hysteresis in membrane displacement analysis is directly linked to the extent of swelling. Thus, hysteretic membranes, although not favorable for accurate pressure sensing, can be used to achieve a bistable effect in some other microdevices (relays, pressure switches, etc.).

11. By selecting the right parameters (heating rate, large channels and thick paste deposition), sag-free, flat membranes in fully integrated LTCC layers may be fabricated. They can be used for fabrication of pressure sensors, micro-fluidic devices, etc. 


\section{Acknowledgments}

The writers are grateful to Dr. Massimo De Petro and Dr. Giovanni Juri of Timcal-Switzerland for providing graphite powders, to Dr. Philip Nising and Dr. Thierry Meyer. Thierry Meyer from Group of Macromolecular Process at EPFL for their help in TGA measurements and to Ms. Caroline Jacq and Mr. Igor Saglini from the Laboratory for Production of Microtechnology (LPM) at EPFL for their layout designs. The financial support of the CTI (Swiss Innovation Promotion Agency) is gratefully acknowledged.

\section{References}

[1] Annas S. 2003 Advances in low temperature co-fired ceramic (LTCC) for ever increasing microelectronic applications Proc. IEEE Conf. on Electronic Components and Technology pp 1691-1693.

[2] Thelemann T, Thust H and Hintz M 2002 Using LTCC for microsystems Microelectronics International 19 19-23.

[3] Kulke R 2001 LTCC-multilayer ceramic for wireless and sensor applications http://www.ltcc.de

[4] Rubio M G, Laguna L M S, Vallejos P E and Aviles J J S 2001 Overview of LTCC tape technology for meso-system technology (MsST) Sensors Actuators A 89 222-241.

[5] Kita J, Dziedzic A, Golonka L J and Bochenek A 2000 Properties of laser cut LTCC heaters Microelectron. Reliab., 40 1005-1010.

[6] Teterycz H, Golonka L J, Kita J, Bauer R, Licznerski B W, Nitsch K and Wisniewski K 1998 New design of an $\mathrm{SnO}_{2}$ gas Sensor on LTCC Sensors Actuators B 47 100-103.

[7] Rubio M G, Laguna L S, Smith M and Aviles J J S 1999 LTCC technology multilayer Eddy-current proximity sensor for harsh environments Proc. International Symposium on Microelectronics 676-681.

[8] Rubio M G, Laguna L S, Smith M, Moffett P J and Aviles J J S 1999 The utilization of LTCC-ML technology for meso-scale EMS, a simple thermistor based flow sensor Sensors Actuators A 73 215-221.

[9] Bauer R, Wolter K-J and Sauer W 1995 Three dimensionally-formed thick-film devices with low temperature co-fired ceramic multilayer technology Proc. ISHM'95 pp 481-486.

[10] Vallejos P E, Zhong J, Rubio M G, Laguna L S, and Aviles J J S 1998 Meso (intermediate)-scale electromechanical systems for the measurement and control of sagging in LTCC structures Proc. Materials Research Society Symposium pp. 73-79.

[11] Bauer R, Luniak M, Rebenklau L, Wolter K J and Sauer W 1997 Realization of LTCC-multilayer with special cavity applications Proc. Materials Research Society Symposium pp 659-664.

[12] US Patent US5601673 Method of making ceramic article with cavity using LTCC tape

[13] Jones W K, Kappagantula S and Wang J 2005 Micro channel fabrication in LTCC substrate, Proceedings of the Ceramic Interconnect Technology Conference (Denver, CO, USA)

[14] Manufacturer's web-site, Harmonics, Inc.: http://www.hmnx.com

[15] Birol H, Maeder T, and Ryser P 2006 Preparation and application of minerals-based sacrificial pastes for fabrication of LTCC structures EMPS 2006: $4^{\text {th }}$ European Microelectronics and Packaging Symposium (Slovenia) pp 57-60.

[16] Park J, Vallejos P E, Laguna L S and Aviles J S 1998 Etching and exfoliation techniques for the fabrication of 3-D meso-scales structures on LTCC tapes Proceedings, IMAPS 1998 Meeting pp 142-147.

[17] Birol H, Maeder T, Jacq C, Corradini G, Fournier Y, Saglini I, Straessler S and Ryser P 2005 Structuration of micro-fluidic devices based on low temperature co-fired ceramic (LTCC) technology Proc. 15th European Microelectronics and Packaging Conference and Exhibition pp 243-247. 
[18] Birol H, Maeder T, Jacq C, Straessler S and Ryser P 2005 Fabrication of LTCC micro-fluidic devices using sacrificial carbon layers International Journal of Applied Ceramic Technology 2 345-354.

[19] Birol H, Maeder T and Ryser P 2006 Processing of graphite-based sacrificial layer for microfabrication of low temperature co-fired ceramics (LTCC) Sensors Actuators A 130-131 560-7

[20] Gunter B H 1993 How statistical design concepts can improve experimentation in the physical sciences Comput. Phys., 7 262-272.

[21] Hellebrand H 1996 Tape Casting, Materials Science and Technology, Vol. 17A, Processing of Ceramics ed R J Brook (Weinheim, Germany: VH) pp 189-265.

[22] Mistler RE 1998 Tape casting: past, present, potential Am. Ceram. Soc. Bull. 82-86.

[23] Mettler Toledo product brochure available on: http://www.mt.com

[24] Datasheet, The Bohlin Controlled Stress Rheometer, Cone/plate CP 4/40, Measuring range: AS8810JB BRI: 100 126/134

[25] http://www2.dupont.com/MCM/en_US/PDF/datasheets/951.pdf.

[26] Prudenziati M 1994 Thick-film Sensors (Amsterdam, Elsevier) pp 6-15.

[27] Pitt K. 2005 Handbook of Thick Film Technology 2nd edition (Isle of Man: Electrochemical Publications) pp 43-62.

[28] Miller L F 1969 Paste transfer in the screening process Solid State Technol 12 (6) 46-52.

[29] Huff M A, Nikolich A D and Schmidt M A 1991 A threshold pressure switch utilizing plastic deformation of silicon Proc. 6th Int. Conf. Solid State Sensors Actuators pp 177-180.

[30] Capanu M, Boyd J G and Hesketh P J, 1996 Bistable microvalve with pneumatically coupled membranes Proc. MEMS '96 384-388.

[31] Arya R, Rashid M M, Howard D, Collins S D and Smith R L 2006 Thermally actuated, bistable, oxide/silicon/metal membranes, J. Micromech. Microeng. 16 40-47. 